\title{
GERAÇÃO, COLETA E IMPACTO DOS RESÍDUOS SÓLIDOS PRODUZIDOS NO CARNAVAL DE RECIFE
}

\section{GENERATION, COLLECTION AND IMPACT OF SOLID WASTE PRODUCED IN THE CARNIVAL IN RECIFE}

\section{Gomes, F.S. ${ }^{1}$, Lima, L.M.P. ${ }^{1}$, Lins, L.M.S.S. ${ }^{1}$, Napoleão, T.H. ${ }^{1}$, Santos, N.D.L. ${ }^{1}$; Vasconcelos, S. D. ${ }^{2}$}

${ }^{1}$ Bacharelandos em Ciências Biológicas - Universidade Federal de Pernambuco (UFPE). Avenida Professor Moraes Rego, s/n, Cidade Universitária, CEP 50670-420, Recife, PE.

${ }^{2}$ Professor Adjunto, Departamento de Zoologia, Centro de Ciências Biológicas Universidade Federal de Pernambuco (UFPE). Avenida Professor Moraes Rego, s/n, Cidade Universitária, CEP 50.670-420, Recife, PE.

Autor para correspondência: Dr. Simão Dias Vasconcelos. Departamento de Zoologia, Centro de Ciências Biológicas - Universidade Federal de Pernambuco (UFPE). Avenida Professor Moraes Rego, s/n, Cidade Universitária, CEP 50.670420, Recife, PE. Fone/Fax: (81) 2126-8353. E-mail: simaovasconcelos@yahoo.com.br, simao@ufpe.br

\section{RESUMO}

A geração excessiva de resíduos sólidos urbanos é um dos problemas ambientais mais críticos das grandes cidades brasileiras. Em períodos de intensa atividade turística, como o Carnaval, há uma sobrecarga na produção de resíduos sólidos, podendo causar impacto ambiental considerável no solo e nos rios. Este trabalho visou investigar o impacto do Carnaval de Recife na geração, coleta e destinação de resíduos sólidos, mediante a análise de documentos e relatórios produzidos pela prefeitura local. Adicionalmente, foi feito um registro fotográfico dos resíduos acumulados nas ruas durante o Carnaval. De 2004 a 2006, foram recolhidas, em média, 395 toneladas de resíduos sólidos durante o Carnaval. Observou-se que, durante os eventos, uma maior quantidade de lixo foi jogada nas ruas e no Rio Capibaribe, o que reflete a falta de conscientização da população. Notou-se também um aumento de $43 \%$, entre 2005 e 2006, na captação do material reciclável descartado no Carnaval. $\mathrm{O}$ aumento na produção de resíduos sólidos durante o Carnaval e a falta de uma postura conservacionista da população ressaltam 
a necessidade se promover campanhas de educação ambiental, mais agressivas visando à redução na produção de resíduos sólidos, especialmente em períodos festivos.

Palavras-chave: Lixo. Reciclagem. Educação ambiental. Limpeza urbana. Poluição.

\begin{abstract}
Excessive solid waste production is one of the most critical environmental problems in large Brazilian cities. In periods of intense touristic activity, such as Carnival, the production of solid waste increases, which may cause considerable environmental impact on the soil and rivers. This study aimed at investigating the impact of Carnival on the generation, collection and destination of solid waste, through the analysis of documents and reports elaborated by the local city council. Additionally, photographic records of garbage disposed on the streets during the Carnival were performed. Between 2004 and 2006, a mean amount of 395 tons of solid waste was collected in the streets of Recife during the Carnival. We observed that, during the festivities, a larger amount of garbage is disposed on the streets, reflecting poor awareness from the population. Also, a $43 \%$ increase in the collection of recyclable material disposed during the Carnival was noticed between 2005 and 2006. The increase in solid waste generation and the lack of a conservationist behavior of the population stress out the need for more aggressive campaigns of environmental education aiming at the reduction of solid waste, especially during popular festivities.
\end{abstract}

Keywords: Garbage. Recycling. Environmental education. Urban cleanliness. Pollution.

\title{
1. INTRODUÇÃO
}

A Associação Brasileira de Normas Técnicas - ABNT - define "resíduos sólidos" como "os restos das atividades humanas, considerados pelos geradores como inúteis, indesejáveis ou descartáveis, podendo se apresentar no estado sólido, semisólido ou líquido, desde que não seja passível de tratamento convencional" (NBR10004) (ASSOCIAÇÃO BRASILEIRA DE NORMAS TÉCNICAS, 2004). Geralmente, não se faz distinção entre os termos "lixo" e "resíduos sólidos".

A origem e a produção dos resíduos sólidos são influenciadas por diversos e complexos fatores, como: aumento populacional, intensidade de industrialização, área relativa de produção, variações sazonais e climáticas, hábitos e costumes da população, nível educacional, poder aquisitivo, equipamentos de coleta, segregação e sistematização no ponto de origem, leis e regulamentações específicas (LIMA, 1995). Conseqüências importantes do acúmulo de lixo incluem a disseminação de agentes 
patogênicos, a diminuição do espaço disponível, a destinação inadequada dos resíduos gerados e o comprometimento do ar, do solo e das águas subterrâneas (FELLENBERG, 1980).

O gerenciamento dos resíduos sólidos deve seguir um modelo de integração entre os processos de coleta, transporte e destinação e, dependendo do tipo de resíduo, as etapas de coleta seletiva, tratamento (incluindo a recuperação de aterros) e aproveitamento (DIAS; PEREIRA, 1999). Este modelo envolve os diversos segmentos da sociedade em etapas articuladas entre si, desde a não-geração até a disposição final, focalizando a elevação da urbanidade e a participação efetiva de uma comunidade comprometida a não sujar as ruas, a reduzir o descarte, a reaproveitar os materiais e reciclá-los antes de encaminhá-los ao lixo (MONTEIRO et al., 2001, ZANTA; FERREIRA, 2003).

A gestão dos resíduos sólidos nas cidades brasileiras apresenta-se de forma bastante heterogênea. Grande parte dos resíduos gerados no país não é regularmente coletada, principalmente nas áreas de baixa renda, sendo vazada em logradouros públicos, terrenos baldios, encostas e cursos d'água (MONTEIRO et al., 2001). Freqüentemente, a administração municipal prioriza áreas comerciais e de renda mais alta (ibid.).

No Brasil, de acordo com a Pesquisa Nacional de Saneamento Básico, se coleta cerca de 228.413 toneladas de resíduos sólidos diariamente. O Nordeste é responsável pela geração de $41.558 \mathrm{t} /$ dia $(18,2 \%$ do total nacional), uma média de $0,87 \mathrm{~kg} / \mathrm{habitante} / \mathrm{dia}$ (INSTITUTO BRASILEIRO DE GEOGRAFIA E ESTATÍSTICA, 2000). Quase a metade (48,2\%) desse resíduo é descartada em lixões a céu aberto, e apenas $14,6 \%$ são destinados a aterros controlados. Pode-se afirmar que a situação do Nordeste é uma das piores do país em termos de formas de destinação mais racionais, como aterro sanitário, reciclagem, incineração ou estação de compostagem (JUCÁ, 2002).

Tradicionalmente considerada uma atividade não-poluente geradora de renda e emprego, o turismo certamente contribui para os problemas associados à geração de resíduos sólidos, especialmente em regiões com baixa infra-estrutura para manejo do lixo. Este é caso de Pernambuco, que devido à sua diversidade cultural e sua base econômica e logística, registrou uma expansão anual de $9,1 \%$ no fluxo global de turistas entre 1990 e 1997. Entre 2000 e 2001, o fluxo de hóspedes na rede formal de hotéis e outras modalidades de hospedagem, concentrado na Região Metropolitana do Recife (RMR), apresentou um crescimento de 12\% (REYNALDO et al., 2005).

Um dos mais importantes atrativos para os turistas é o Carnaval, festa popular tradicional no Recife, que se expande além da duração oficial de quatro dias para incluir as semanas que o antecedem. A quantidade de resíduos sólidos gerados na cidade, representados por papel, plásticos e, principalmente, embalagens de bebidas latas, vidros, e plásticos rígidos - aumenta consideravelmente neste período. Conhecida como Capital do Frevo e do Maracatu, Recife tem uma das maiores festas de carnaval do país, sendo palco de manifestações culturais concentradas nos pólos 
de animação da cidade. O ponto máximo é o desfile do Bloco do Galo da Madrugada, que atrai cerca de 1,5 milhão de pessoas a cada ano, atravessando as pontes e ruas do centro histórico da cidade. Apesar de sua beleza, tal evento gera uma assombrosa quantidade de lixo (80 t), segundo a Empresa de Manutenção e Limpeza Urbana de Recife (EMLURB) (RECIFE, 2004).

Embora campanhas educativas busquem promover a conscientização popular sobre a importância da correta destinação do lixo e do hábito da reutilização e reciclagem, o conhecimento sobre geração, manejo e destinação dos resíduos sólidos produzidos no Carnaval é ainda escasso. Tais informações têm fundamental importância para fornecer bases para futuras ações governamentais e/ou sociais a fim de minimizar os impactos sócio-ambientais do lixo gerado nessa festividade. Partindo dessa necessidade, este trabalho teve como objetivo analisar a produção, limpeza e destinação dos resíduos sólidos gerados no Carnaval de Recife nos últimos três anos.

\section{MATERIAIS E MÉTODOS}

\subsection{Descrição da Área}

O município de Recife situa-se 4 metros acima do mar, em região litorânea cortada por rios e manguezais que apresentam uma dinâmica de equilíbrio bastante frágil. De acordo com o censo de 2000, 1.422 .905 pessoas moram em Recife, o que corresponde a uma densidade demográfica de aproximadamente 6,5 mil habitantes $/ \mathrm{km}^{2}$, concentrados $(99 \%)$ nas zonas urbanas do município (REYNALDO et al., 2005, IBGE, 2006).

Os resíduos sólidos urbanos gerados no Recife são confinados no Aterro Controlado da Muribeca, o qual está dividido em células de depósito de resíduos, com base em critérios de engenharia ambiental (JUCÁ et al., 1999). Além da ausência de um aterro sanitário, a cidade enfrenta graves problemas de pobreza e de degradação dos recursos naturais e cursos d'água e do ambiente construído, como as demais metrópoles brasileiras (REYNALDO et al., 2005). O período chuvoso, que se estende de abril a setembro, é constantemente acompanhado de alagamentos e inundações, resultantes, em grande parte, do acúmulo de lixo nas galerias pluviais.

\subsection{Natureza da Pesquisa}

A investigação envolveu a análise de documentos relacionados à produção e destinação dos resíduos sólidos gerados no carnaval da cidade. Foram analisados relatórios mensais e trimestrais da Gerência de Coleta Seletiva, da Gerência de Fiscalização e Limpeza e da Gerência Operacional de Gestão e Informação da Diretoria de Limpeza Urbana da EMLURB. Os dados coletados (quantidade mensal de lixo gerada, quantidade de lixo gerada no período de carnaval e dados sobre a limpeza do Rio Capibaribe) foram referentes aos três primeiros meses dos anos de 2004, 2005 e 2006 (RECIFE, 2004, 2005, 2006). 
Considera-se como período de carnaval os cinco dias - da sexta-feira até a terça-feira imediatamente posterior. A quantidade total de resíduos sólidos gerados em cada mês engloba todos os segmentos da limpeza urbana, excetuando-se o lixo hospitalar, tratado por procedimento diferenciado segundo a legislação. Os dados referentes ao Carnaval contabilizam o lixo gerado nos eventos ocorridos nos pólos de animação da cidade e no desfile do Bloco do Galo da Madrugada. De 2004 a 2006, o Carnaval do Recife foi realizado em oito pólos principais, localizados principalmente no centro histórico (Marco Zero, Praça do Arsenal da Marinha, Cais da Alfândega, Avenida Dantas Barreto, Pátio de São Pedro, Pátio do Terço e Pátio de Santa Cruz) e mais oito pólos descentralizados nos bairros de Santo Amaro, Chão de Estrelas, Casa Amarela, Nova Descoberta, Alto José do Pinho, Várzea, Jardim São Paulo e Ibura, além de 26 pólos menores espalhados nos bairros da cidade.

Adicionalmente, foram documentados com câmera digital (resolução 5.1 megapixels) vários pontos no percurso do bloco do Galo da Madrugada e em um trecho do Rio Capibaribe no centro da cidade. As fotografias foram tiradas imediatamente após o desfile do Bloco e 24 horas depois para comparação da situação do lixo acumulado. Os três pontos foram novamente fotografados no mês de abril, no período de baixa estação.

\section{RESULTADOS E DISCUSSÃO}

De acordo com as planilhas da Diretoria de Limpeza Urbana da EMLURB (RECIFE, 2004, 2005, 2006), uma média de 73 mil toneladas (t) por mês de resíduos sólidos foi recolhida no primeiro trimestre dos últimos três anos no Recife (Tabela 1). A quantidade de lixo gerada diretamente nos pólos de animação do Carnaval representou aproximadamente $0,58 \%$ da média recolhida no mês de fevereiro dos anos de 2004, 2005 e 2006 (Tabela 2). Apesar do acréscimo ter aparentemente um pequeno impacto, a sobrecarga é amplificada porque esse volume de lixo foi produzido em espaço - centro e pólos culturais da cidade - e tempo reduzidos, sendo boa parte recolhida apenas no desfile do Bloco do Galo da Madrugada.

Segundo o Relatório Trimestral da Diretoria de Limpeza Urbana, no Carnaval uma média de cerca de 400 t de resíduos sólidos é gerada no desfile do Galo da Madrugada e nos pólos de animação do centro da cidade. Somente no sábado, quando ocorre o desfile do bloco, foram recolhidos $48 \%$ do total de lixo coletado em todo o Carnaval de 2006, valor 3,7 vezes maior que a média dos outros quatro dias. A Tabela 2 mostra que, enquanto a quantidade total de resíduos não-recicláveis recolhidos em fevereiro diminuiu nos últimos anos, no período carnavalesco a geração de lixo aumentou.

A quantidade gerada demanda um re-escalonamento do trabalho por parte da administração pública, com maior deslocamento de mão-de-obra (985 garis em 2006) e mais gasto com material utilizado para a limpeza somente dos focos de animação. 
Para desinfecção das ruas, em 2006, foram utilizados 1.601 .000 litros de água, 3.600 litros de detergentes, 10.000 litros de essências e 80 litros de creolina. Considerandose que o escoamento natural desse material líquido acaba atingindo os corpos hídricos locais, grande parte desse contaminante tem como destino o Rio Capibaribe, que banha o centro da cidade.

Tabela 1 - Resíduos sólidos totais (em toneladas) recolhidos no Recife no primeiro trimestre dos anos de 2004, 2005 e 2006. O Carnaval dos três anos ocorreu no mês de fevereiro.

\begin{tabular}{|c|c|c|c|}
\hline Mês & $\begin{array}{c}2004 \\
\text { Lixo (t) }\end{array}$ & $\begin{array}{c}\text { Ano } \\
2005 \\
\text { Lixo (t) }\end{array}$ & $\begin{array}{c}2006 \\
\text { Lixo (t) }\end{array}$ \\
\hline Janeiro & 81.397 & 74.463 & 67.096 \\
\hline Fevereiro & 74.536 & 73.014 & 57.744 \\
\hline Março & 82.663 & 80.159 & 70.685 \\
\hline
\end{tabular}

Fonte: RECIFE (2004, 2005, 2006)

A destinação final correta de resíduos sólidos recicláveis por meio do programa de coleta seletiva foi implantada pela Prefeitura da Cidade do Recife (PCR), através da EMLURB, em 1993. Além dos Postos de Entrega Voluntária (PEVs), da coleta porta a porta, dos núcleos permanentes de catadores e dos núcleos de triagem, durante o Carnaval postos especiais do programa são montados no centro da cidade, para facilitar o recolhimento do material reciclável descartado.

Segundo dados da Gerência de Coleta Seletiva da EMLURB, somente nos pólos de animação cerca de $20 \mathrm{t}$ de material reciclável foram recolhidas no carnaval de 2006. Esse valor foi 43\% maior que o total recolhido em 2005 (14 t). Esses dados mostram um aumento na captação do material reciclável descartado no carnaval.

Evidenciando a elevada proporção de lixo gerada somente no desfile do Galo da Madrugada, uma enorme quantidade de resíduos foi observada nas ruas analisadas, acumulando-se embaixo dos palcos, nas calçadas, no pavimento das ruas. Ao se repetir o trajeto do desfile, resíduos sólidos acumulados nas ruas foram registrados em todos os quarteirões, freqüentemente entupindo galerias (Figuras 1 e 2). No dia seguinte, ainda se observaram grandes pilhas de lixo reciclável separadas de pilha de lixo não-reciclável, em virtude da enorme quantidade gerada, apesar de o trabalho de limpeza das ruas ter avançado consideravelmente. Fora do período de Carnaval, uma quantidade muito menor de resíduos foi observada nas ruas. A partir dessa observação direta, notou-se que a maioria do material reciclável não é depositada em locais apropriados pelos próprios foliões e sim, posteriormente, recolhido pela 
empresa de limpeza urbana, o que reflete a falta de conscientização por parte da população - nativo ou turista.

Tabela 2 - Resíduos sólidos totais recolhidos no Recife no mês de fevereiro dos anos de 2004, 2005 e 2006 e recolhidos somente no desfile do Bloco do Galo da Madrugada e nos pólos de animação do Carnaval.

\begin{tabular}{ccccc}
\hline & $\mathbf{2 0 0 4}$ & $\mathbf{2 0 0 5}$ & $\mathbf{2 0 0 6}$ & Média \\
\hline Lixo total (t) & 74.536 & 73.014 & 57.744 & 68.431 \\
Lixo do carnaval (t) & 373 & 401 & 411 & 395 \\
Lixo do carnaval em relação ao total (\%) & 0,50 & 0,54 & 0,71 & 0,58 \\
\hline
\end{tabular}

Fonte: RECIFE $(2004,2005,2006)$

O encerramento do desfile do Bloco do Galo da Madrugada ocorre na Ponte Duarte Coelho sobre o Rio Capibaribe. A contaminação da água foi observada de duas maneiras: além de receber o material de limpeza utilizado na desinfecção das ruas, o rio também funciona como depósito de boa parte dos resíduos produzidos no desfile.

A geração excessiva e o manejo inadequado do lixo, resultantes da falta de consciência da população, quando associadas a políticas ineficientes por parte dos órgãos públicos, acabam por amplificar o processo de degradação ambiental. No caso da disposição inadequada de resíduos nas águas superficiais, esse problema agravase, com efeitos na natureza incalculáveis, relacionados diretamente à escassez e à contaminação da água e a doenças associadas à poluição ambiental (OLIVEIRA; JUCÁ, 2004).

O Rio Capibaribe, o mais importante de Recife, com uma extensão total de 270 $\mathrm{km}$ da nascente até a sua foz no Oceano Atlântico, recebe resíduos industriais e domésticos ao longo de todo seu percurso, funcionando, em certos trechos, praticamente como um lixão a céu aberto. Tentando contornar este problema, a EMLURB, através da Diretoria de Limpeza Urbana (DLU), implantou o Barco ECO VIDA para a limpeza do leito do rio em toda sua extensão, navegável, em Recife, atendendo ao termo de compromisso celebrado entre o Ministério Público e a EMLURB. São duas embarcações que fazem um percurso de cerca de $23 \mathrm{~km}$, de segunda a sábado, das $8 \mathrm{~h}$ às $17 \mathrm{~h}$, recolhendo detritos flutuantes e mapeando pontos críticos de grande acúmulo de lixo. 


\begin{tabular}{|l|r|}
\hline Recebido em: 01/08/2006 & HOLOS Environment, v.7 n.2, 2007 - P. 198 \\
\hline Liberado para Publicação em: $21 / 10 / 2007$ & ISSN:1519-8634 (ON-LINE) \\
\hline
\end{tabular}
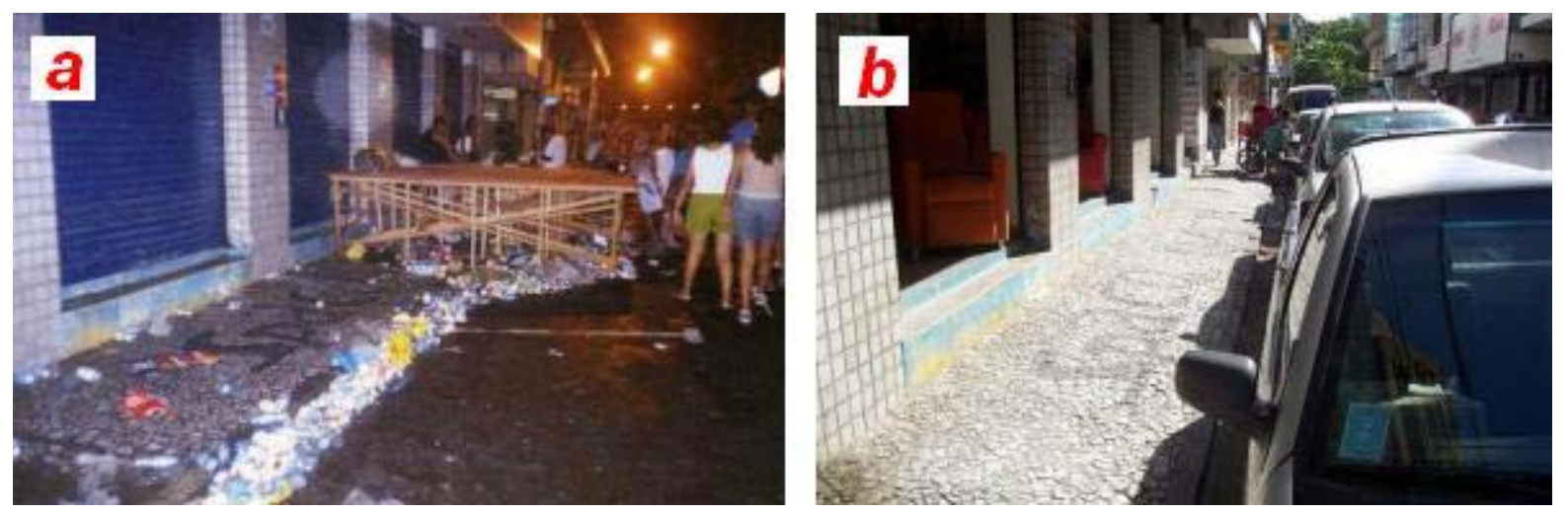

Figura 1. Trecho da Rua Marquês do Herval, localizada no centro da cidade do Recife, em dois momentos: (a) logo após o desfile do Bloco do Galo da Madrugada em fevereiro de 2006 e (b) em período de baixa estação - abril de 2006.

Sendo o serviço de coleta o mesmo durante os três anos, a Tabela 3 mostra que, apesar da quantidade menor de dias de atividade dos barcos, o volume recolhido no mês de fevereiro supera o de janeiro nos três anos. Dentre os trimestres analisados, a média diária recolhida em fevereiro só não foi a maior em 2005. O carnaval dos anos analisados ocorreu no mês de fevereiro e foi um dos fatores responsáveis por esse aumento.
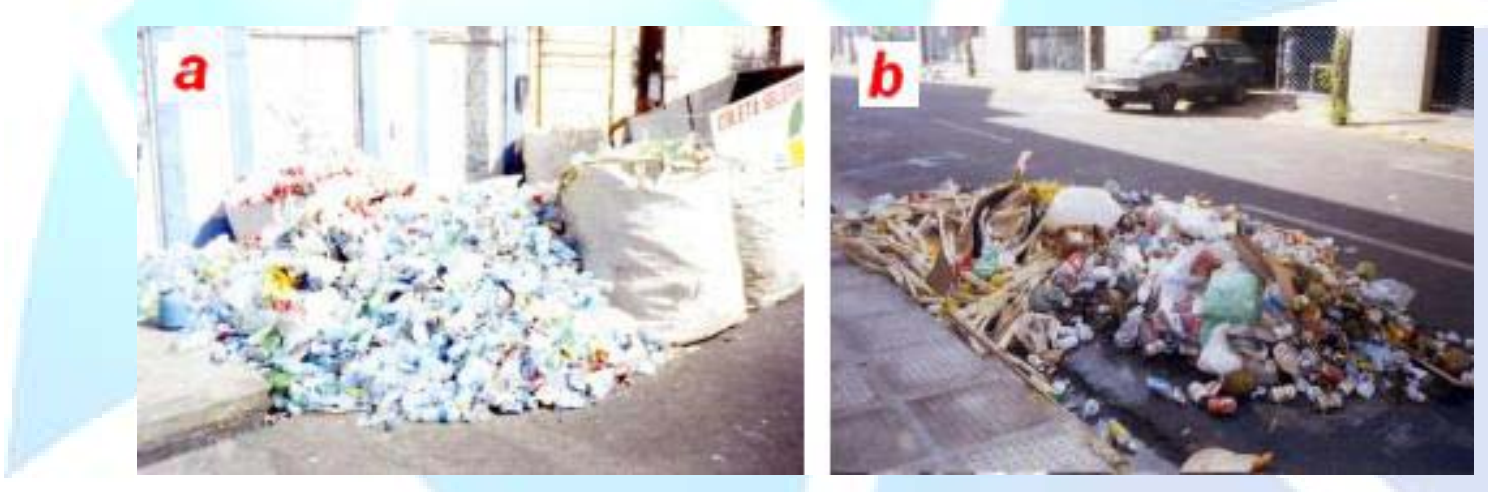

Figura 2. Pilhas de lixo reciclável (a) e não-reciclável (b), observadas no centro da cidade no dia seguinte ao desfile do Bloco do Galo da Madrugada em 2006.

Tabela 3 - Número de dias de atividade dos barcos e quantidade de lixo recolhida no Rio Capibaribe no primeiro trimestre dos anos de 2004, 2005 e 2006.

\begin{tabular}{ccccccc}
\hline \multirow{2}{*}{ Mês } & \multicolumn{2}{c}{$\mathbf{2 0 0 4}$} & \multicolumn{2}{c}{ Ano } & \multicolumn{2}{c}{$\mathbf{2 0 0 6}$} \\
& Lixo (t) & Dias & Lixo (t) & Dias & Lixo (t) & Dias \\
\hline Janeiro & 112,72 & 26 & 106,10 & 25 & 135,20 & 26 \\
Fevereiro & 113,76 & 24 & 110,24 & 22 & 155,1 & 23 \\
Março & 119,56 & 27 & 121,69 & 23 & 177,42 & 27 \\
\hline
\end{tabular}

Fonte: RECIFE $(2004,2005,2006)$ 
Nas grandes cidades, a ação da população em poluir o espaço urbano é muito maior que a capacidade de o poder público de limpá-lo (TAVARES; FREIRE, 2003). Considerando as proporções do Bloco do Galo da Madrugada, que reúne tantas pessoas em um espaço reduzido, os prejuízos se agravam, pois boa parte do material que poderia ter sido descartado apropriadamente acumula-se e não é recolhido. A falta de identificação de locais apropriados para o descarte e a própria natureza da atividade - de lazer/prazer, inconseqüente e transitória, freqüentemente envolvendo consumo de bebida alcoólica - não têm favorecido uma postura conservacionista dos envolvidos. Por outro lado, é durante o Carnaval que uma imensa legião de pessoas sem emprego dedica-se à catação de embalagens de plástico, vidro, e principalmente alumínio, para reciclagem.

Tavares e Freire (2003) destacam a visão de que a população brasileira, em geral, não vê a rua como espaço seu, e sim do governo, tendo dificuldade em considerar como "preservação do meio ambiente" o cuidado com a rua, o bairro e a cidade, associando esse conceito somente à proteção de animais e florestas e deixando de se importar com os destinos do lixo das vias públicas e cursos d'água que atravessam as cidades. Quando se enaltece a beleza das festividades populares de rua, como o Carnaval do Recife, é comum esquecer-se do outro lado da festa: o impacto ambiental causado pela geração e destinação inadequada dos resíduos sólidos.

Desta forma, é fundamental a promoção da conscientização da população, através de medidas que levem ao aumento do nível de informação - e ação - com eliminação de desperdícios e compartilhamento de responsabilidades (RIBEMBOIM, 1997). A prefeitura deve aprimorar não só o seu papel técnico de responsável pela limpeza do espaço público, como também educacional. A adoção de campanhas intensivas durante o Carnaval (principalmente em televisão, rádio, revistas, internet e jornais) tem sido um passo importante, além da ampliação de discussões relacionadas à problemática do lixo nas universidades e escolas. Também é essencial a mobilização de grupos da sociedade civil (empresários locais, imprensa, comunidade acadêmica, ONGs, etc.) para garantir que a atividade turística e de lazer ocorra com o mínimo de impacto ao meio ambiente local.

\section{CONCLUSÃO}

A geração de resíduos sólidos durante o Carnaval de Recife vem aumentando nos últimos anos. Não se percebe um comprometimento da população - nativa ou turista - em reduzir a produção e descartar adequadamente os resíduos em locais apropriados, fato evidenciado pelo acúmulo de lixo nas calçadas, ruas, galerias e no Rio Capibaribe. A limpeza e a desinfecção dos locais de festividades acabam por poluir adicionalmente os rios locais. A conscientização da população e a adoção de campanhas conjuntamente com a criação de locais especiais para descarte do material 
residual proveniente do Carnaval são as principais etapas para tentar minimizar o problema.

\section{AGRADECIMENTOS}

Agradecemos aos funcionários da EMLURB Carlos Melo (Gerência Operacional de Gestão e Informação), André Santos (Gerência de Coleta Seletiva), Antônio Avelino Pontes (Gerência de Fiscalização e Limpeza), Davi Sampaio (Gerência Operacional de Acompanhamento e Planejamento) e a Adauto Lins, Gerente do Aterro Controlado da Muribeca.

\section{REFERÊNCIAS}

ASSOCIAÇÃO BRASILEIRA DE NORMAS TÉCNICAS. Resíduos sólidos: classificação: NBR-10004. Rio de Janeiro, 2004.

DIAS, M. C. O.; PEREIRA, M. C. B (Coord.). Manual de impactos ambientais: orientações básicas sobre aspectos ambientais de atividades produtivas. Fortaleza: Banco do Nordeste, 1999.

FELLENBERG, G. Introdução aos problemas da poluição ambiental. São Paulo: Editora da Universidade de São Paulo, 1980.

INSTITUTO BRASILEIRO DE GEOGRAFIA E ESTATÍSTICA. Pesquisa nacional de saneamento básico 2000. Disponível em: http://www.ibge.gov.br. Acesso em: 14 maio 2006.

JUCÁ, J. F. T. Destinação final dos resíduos sólidos no Brasil: situação atual e perspectivas. In: SIMPÓSIO LUSO-BRASILEIRO DE ENGENHARIA SANITÁRIA E AMBIENTAL, 10., 2002, Braga, Portugal. Anais... 1 CD-ROM.

JUCÁ, J. F. T.; MARIANO, M. O. H.; MELO, V. L. A. Recalques e decomposição da matéria orgânica em aterros de resíduos sólidos na região metropolitana do Recife. In: CONGRESSO BRASILEIRO DE ENGENHARIA SANITÁRIA E AMBIENTAL; FEIRA INTERNACIONAL DE TECNOLOGIAS DE SANEAMENTO AMBIENTAL, 20., 1999, Rio de Janeiro. 1 CD-ROM.

LIMA, L. M. Q. Lixo: tratamento e biorremediação. 3. ed. São Paulo: Hemus, 1995. 
MONTEIRO, J. H. P.; FIGUEIREDO, C. E. M.; MAGALHÃES, A. F.; MELO, M. A. F.; BRITO, J. C. X.; ALMEIDA, T. P. F.; MANSUR, G. L.; ZVEIBIL, V. Z. Manual de gerenciamento integrado de resíduos sólidos. Rio de Janeiro: IBAM, 2001.

OLIVEIRA, F. J. S.; JUCÁ, J. F. T. Acúmulo de metais pesados e capacidade de impermeabilização do solo imediatamente abaixo de uma célula de um aterro de resíduos sólidos. Engenharia Sanitária e Ambiental, Rio de Janeiro, v. 9, n. 3, p. 211-217, 2004.

Disponível

em: http://www.scielo.br/scielo.php?script=sci abstract\&pid=S1413$\underline{41522004000300007 \& \operatorname{lng}=p t \& n r m=i s o \& t \operatorname{lng}=p t}$ Acesso em: 31 jan. 2007.

RECIFE. Diretoria de Limpeza Urbana. Empresa de Manutenção e Limpeza Urbana. Relatório trimestral: janeiro/ fevereiro/ março, 2004.

. Relatório trimestral: janeiro/ fevereiro/ março, 2005.

. Relatório trimestral: janeiro/ fevereiro/ março, 2006.

REYNALDO, A.; ANDRADE, M.; SABATÉ, J.; ARAÚJO, A. J.; ARAÚJO, T. P. (Org.). Metrópole estratégica: região metropolitana do Recife. Recife: PROMETRÓPOLE, FIDEM, 2005.

RIBEMBOIM, J. Mudando os padrões de produção e consumo: textos para o século XXI. Brasília: Edições IBAMA, 1997.

TAVARES, C.; FREIRE, I. M. "Lugar de lixo é no lixo": estudo de assimilação da informação. Ciência da Informação, Brasília, v. 32, n. 2, p. 125-135, 2003. http://dx.doi.org/10.1590/S0100-19652003000200013

ZANTA, V. M.; FERREIRA, C. F. A. Gerenciamento integrado de resíduos sólidos. In: CASTILHO, A. B. (Coord). Resíduos sólidos urbanos: aterro sustentável para municípios de pequeno porte. Florianópolis: PROSAB, 2003. p. 1-18 